\title{
EFFECTS OF STRATEGIC DECISIONS ON PERFORMANCE OF KENYAN UNIVERSITIES
}

\author{
LUCY WANZA ${ }^{1}$, JOSEPH F. NTALE ${ }^{2} \&$ MICHAEL KIRWAKORIR ${ }^{3}$ \\ ${ }^{I}$ The Catholic University of Eastern Africa, Gaba Campus, Eldoret, Kenya \\ ${ }^{2}$ The Catholic University of Eastern Africa, Nairobi, Kenya
}

${ }^{3}$ Professor, Moi University, School of Business and Economics, Department of Management Science, Eldoret, Kenya

\begin{abstract}
The university education sector is becoming very competitive due to changes in the business environment. In order to be successful strategic decisions are a key to improving performance of universities. The purpose of this study is to establish the effects of strategic decisions on performance of universities in Kenya. Systems theory provided a theoretical basis for the study. The study adopted explanatory - cross sectional survey research design. Respondents were selected using stratified and simple random sampling techniques. A questionnaire was used to collect primary data. Data was analyzed using descriptive and inferential statistical techniques. Descriptive statistics such as means and standard deviations were used, while in inferential statistics, structural equation modeling was used for model specification and hypothesis testing. The study unveiled that strategic decisions have a significant effect on performance of universities. The study concluded strategic decisions positively influence performance of universities. Top management in universities should make strategic decisions that have a positive long term effect on performance of universities. The study recommended that top management should evaluate all strategic decisions before implementation and also a further research to be conducted in other sectors to test the conceptualized model.
\end{abstract}

KEYWORDS: Strategic Decisions, Investment, Diversification, Expansion \& Performance of Universities

Received: Aug 23, 2017; Accepted: Sep 14, 2017; Published: Oct 05, 2017; Paper Id.: IJBMROCT20174

\section{INTRODUCTION}

Strategic decision-making has emerged as one of the most active areas of current strategic management research (Papadakis, 1998). In the $21^{\text {st }}$ century, organizations are experiencing strategic changes that affect performance. Strategic decisions are long term, highly unstructured, complex, and inherently risky and have great impact on the future of the organization (Papadakis, 1998). Further, the author contended that, according to environmental determinism, strategic decisions and processes are expressing adapt to opportunities, threats, constraints and other characteristics of the environment. Successful strategic decision making would enable an organization to maintain a competitive position, align internal operations with external environments and survive threats and challenges, while conversely, because of their magnitude, a single, poorly made strategic decision can lead to its demise and result in corporate embarrassment, large economic losses for stakeholders or even bankruptcy (Mueller et al., 2007). An understanding of strategic decisions is vital at all levels in order to influence performance of universities. Organization's performance is measured considerably based on their financial achievements and growth (Rehman, Khalid \& Khan, 2012). University performance, therefore involves performing certain activities to ensure achievement of goals, monitor progress, and make adjustments to achieve 
those goals more effectively and efficiently.

Today's universities have to deal with dynamic and uncertain environments. In order to be successful, universities must be strategically aware. They must understand how changes in their competitive environment are unfolding. They should actively look for opportunities to exploit their strategic abilities, adapt and seek improvements in every area of the business, building on awareness and understanding of current strategies and successes (Papulova \& Papulova, 2006). The authors noted that, decisions by managers have a strategic impact and contribute to strategic change. Decisions are at the heart of the success of any organization, and at times there are critical moments, when they can be difficult to make. A decision usually involves three steps: (1) Recognition of a need - dissatisfaction within oneself (a void or need); (2) a decision to change - to fill the void or need; and (3) a conscious dedication to implement the decision (Arsham, 2010).

The top management consists of an organization's executive, who forms the inner cadre or circle of people, who collectively formulate, articulate, and execute the strategic and tactical moves of the organization (Eisenhardt, Kahwajy \& Bourgeois, 1997). The qualities of this team are the essential foundation for a successful strategic process within the organization (Hambrick, 1987). Their strategic decisions and the acceptance of the decisions by members of the organization, arguably influence firm performance (Amason, 1996). More directly Cheng, Wang and Zhang, (2011) amplified the reality that top management makes strategic decisions, that are critical to organizational performance. The strategic decisions are basically the essential core of the strategic management (Kantardjieva, 2015). She stresses that the process of strategic decision making the choice of the most viable alternatives is crucial. She further states that today's strategic decision making requires significant or modest investment in terms of dimensions and the degree of change. In addition, the study of organizational performance and strategic decision-making seems to be problematic and much of the research has yielded conflicting results (Papadakis, 1998). This gap requires further investigation on the effect of strategic decisions on performance of universities in Kenya.

Over the last decades, a new research on how executives influence strategic decisions and organizational outcomes has received a great attention in the area of strategic management and organizational studies (Nooraie, 2012). In the strategic management research, executives play a dominant role in formulating corporate strategy and in determining the direction of the firm (Westphal \& Fredrickson, 2001). But empirical research has not been extended to rigorous investigation on the effects of strategic decisions on organizational performance (Nemati, 2010). This current study, therefore conceptualizes that strategic decisions affects universities' performance. Introduction of strategic decisions in universities will improve performance in terms of quality in research, teaching, collaborations and enrollment growth rate. Universities are the highest level of knowledge transmission whereby the nation greatly depends upon for its economic development.

\section{LITERATURE REVIEW}

\section{Theoretical Perspectives}

The concept of performance of universities is informed by resource based view (RBV) theory. The RBV theory is one of the most widely accepted theories of strategic management. Penrose (1959) was one of the first scholars to recognize the importance of resources to an arm's competitive position (Kariuki, 2014). She argued that, an arm's growth, both internally and then externally through merger, acquisition, and diversification, is due to the manner in which, its resources are employed. She began by arguing that, a firm consists of a collection of productive resource and continued by suggesting that, these resources may only contribute to a firm's competitive position, to the extent that they are exploited in 
such a manner that, their potentially valuable services are made available to the firm. Universities that possess unique resources such as inimitable skills, technologies can contribute to their performance. For instance: in terms of qualified staff, lecturers' qualifications, infrastructures, information resources (library), academic programs will enhance competitiveness of a university. Aside from Penrose (1959), Rubin (1973) is argued to be one of the few scholars to conceptualize firms, as resource bundles prior to the formal origins of the RBV (Wernerfelt, 1984). Like Penrose, Rubin recognized that resources were not of much use, by themselves. Instead of merely possessing resources, Rubin (1973) argued, that firms must process raw resources, to make them useful. Barney (1991) argued that, firms that possessed resources that were valuable and rare would attain a competitive advantage, and enjoy improved performance in the short term.

According to the resources-based theory, the bundles of competitive resources can be identifiable in higher education institutions. For higher education institutions, such resources might include the reputation of certain departments, the grouping together on areas of specialist expertise, and the development of technical patents and so on (Lynch \& Baines, 2004). According to Barney (1991) location is a firm physical capital resource. The main resource of university is generally about people resource, which might be attracted by salary or investment facilities in another institution (Finkelstein, Hambrick \& Cannella, 1996), and so higher education resources may not be imperfectly mobile. A basic definition of the competitive resources of a university identifies tangible, intangible and organizational assets (Grant, 1996). Lynch and Baines (2004) stated that tangible resources might include campus location, building capacity, conference facilities and research facilities. Intangible resources generally include such items as patents, teaching and research performance, service levels and technology and the geographical location of a service. In a university, such intangible resources might include some of the above and may include employees/associates (for example, eminent professors, renowned authors and distinguished lecturers). Scholars are of the view that the sources of competitive advantages for universities are thought to be the reputation of the institution, the curriculum and educational standards, cost, location and student activities (Blustain, Goldstein \& Lozier, 1998).

However, RBV theory has been critiqued by authors and researchers that it's not the only resources that contribute to the competitive advantage of an organization. There are other factors, for instance like in university resources have to be combined with other factors to ensure that they achieve competitive advantage. One version of the sufficiency critique concerns the lack of empirical support for the RBV. It has been noted several times that, the possession of resources is not sufficient and it is only by being able to deploy these, that sustained competitive advantage (SCA) can be attained (Peteraf\& Barney, 2003). In their study Okwiri and Mbeche (2014) observed that, the stability of the operating environment can no longer be assumed, a paradigm shift in strategic decision-making by top management becomes unavoidable. Astley and Van de Ven (1983) argue that, decision makers have significant influence on the organization's performance.

This paper was guided by one objective: to investigate the effects of strategic decisions on the performance of Kenyan universities. The research hypothesis stated that: There is a significant relationship between strategic decisions and performance of Kenyan universities.

\section{RESEARCH METHODOLOGY}

The study was undertaken from eight universities in Kenya. It utilized explanatory cross-sectional survey design because it minimizes bias and provides an opportunity for probability sampling, which maximizes reliability of data 
collected (Taurus, 2014). The target population for this study included all top management and heads of department from the eight selected universities. The total number of the staff was 876 by the time of conducting the study from which a sample size was 321 representing $36.6 \%$ of the respondents were selected. The study utilized stratified sampling technique to obtain employees from the six departments. The researcher collected primary data using a self-administered questionnaire. The researcher used simple random sampling technique to select employees from each department.

\section{Measurement of Variables}

The researcher developed the measurement items to test the effect of strategic decisions on university performance. In this study, the researcher conducted a factor analysis to analyze the interrelationships among the variables of the study (Cooper \& Schindler, 2015). The researcher used principle component's method with varimax rotation to identify the factors with higher loadings that were used for further analysis.

Kaiser-Meyer-Olkin measure of sampling adequacy test $(0.834)$ and the Bartlett's test of sphericity $(\mathrm{p}<0.000)$ was realized. Reliability of the ten items measuring strategic decisions was 0.903 on the basis of Cronbach's Alpha reliability estimate, which falls in the recommended lower limit reliability estimate of 0.70 (Hair et al., 2006). The construct was categorized into three different sub-dimensions, namely: diversification, investment and expansion (Table 2).

As shown in table 1 below, ten items were used to measure strategic decision and ten items were utilized to measure performance of universities. The researcher used a five point Likert scale type; strongly disagree (SD) equals to one, disagree (D) equals to two, undecided equals to three (U), agree (A) equals to four and strongly agree (SA) equals to five was used to measure these items.

\section{RESULTS AND DISCUSSIONS}

\section{Descriptive Statistics for Strategic Decisions}

Table 1 illustrates the results on descriptive statistics of strategic decisions revealed that the top management incorporates 'quality vision' into the goals and objectives of the university (mean $=3.93, \mathrm{SD}=0.905$ ). This implies that the top management has a clear vision of a desired future, including desired outcomes; hence they have identified goals and objectives to provide a strategic direction for the university. Strategy implementation is integrated within quality management practices (mean $=3.93, \mathrm{SD}=0.903$ ). Also, university top management provides guidelines for the adoption of QMPs (mean $=4.1, \mathrm{SD}=0.826$ ). This makes it easier for the employees to follow the guidelines and thereby making it easier to adopt quality management practices. As well, the top management ensures the presence of quality improvement designs in form of structure, allocation of resources and quality culture (mean $=3.83, \mathrm{SD}=1.07$ ). The top management can therefore set priorities and revise objectives in terms of changing demands and ensuring that there is allocation of resources and quality culture.

Table 1: Descriptive Statistics for Strategic Decisions

\begin{tabular}{|l|c|c|c|c|c|}
\hline & Mean & $\begin{array}{c}\text { Std. } \\
\text { Deviation }\end{array}$ & Skewness & Kurtosis & $\begin{array}{c}\text { Cronbach } \\
\text { Alpha if Item } \\
\text { Deleted }\end{array}$ \\
\hline $\begin{array}{l}\text { Top management incorporates ‘quality vision' into } \\
\text { the goals and objectives of the university }\end{array}$ & 3.93 & $\begin{array}{c}0 \\
.905\end{array}$ & -1.111 & 1.711 & .894 \\
\hline $\begin{array}{l}\text { Strategy implementation is integrated within quality } \\
\text { management practices }\end{array}$ & 3.93 & 0.903 & -1.258 & 1.895 & .891 \\
\hline University top management provide guidelines to & 4.1 & 0.826 & -1.493 & 3.714 & \\
\hline
\end{tabular}




\begin{tabular}{|c|c|c|c|c|c|}
\hline the adoption of QMPs & & & & & .884 \\
\hline \multicolumn{6}{|c|}{ Table 1: Contd., } \\
\hline $\begin{array}{l}\text { Top management ensures the presence of quality } \\
\text { improvement designs in form of structure, } \\
\text { allocation of resources and quality culture }\end{array}$ & 3.83 & 1.07 & -1.049 & 0.488 & .888 \\
\hline $\begin{array}{l}\text { Top Management plays a critical role in all key } \\
\text { strategic decisions }\end{array}$ & 4.14 & 0.817 & -0.945 & 1.074 & .890 \\
\hline $\begin{array}{l}\text { Non-managerial employees make significant } \\
\text { contributions to university strategic decisions }\end{array}$ & 3.64 & 1.058 & -0.593 & -0.321 & .890 \\
\hline $\begin{array}{l}\text { Top management make decisions on all capital } \\
\text { investments of the university }\end{array}$ & 4.31 & 0.662 & -1.057 & 3.14 & .898 \\
\hline $\begin{array}{l}\text { Top management are involved in decisions about } \\
\text { university expansions }\end{array}$ & 4.34 & 0.692 & -1.152 & 2.818 & .910 \\
\hline $\begin{array}{l}\text { Top management incorporates strategic decisions on } \\
\text { income generating projects for the university }\end{array}$ & 4.09 & 0.973 & -1.514 & 2.513 & .888 \\
\hline $\begin{array}{l}\text { Top management decision-making and past } \\
\text { performance affect future decision-making } \\
\text { processes and outcomes of our university }\end{array}$ & 4.08 & 0.84 & -1.494 & 3.483 & .896 \\
\hline Composite Mean & 4.04 & 0.8745 & -1.167 & 2.052 & \\
\hline Cronbach's Alpha & 0.903 & & & & \\
\hline
\end{tabular}

Source: Research data, 2017

\section{Factor Analysis for Strategic Decisions}

The factor analysis for strategic decisions shows that all the ten measurement items scored above the threshold of 0.50. All the three factors were extracted that measure strategic decisions: diversification, expansion and investment and results of factor analysis as in Table 2.

Results in table 2 revealed that the total variance explained showed that factor 1 accounted for considerably more variance than the remaining two $(54.273 \%$ compared to $16.048 \%$ and $8.426 \%)$, however, after rotation sums of squared loading accounted for only $34.176 \%$ of variance (compared to $22.295 \%$ and $22.276 \%$ respectively). The three factors accounted for $78.747 \%$ indicating it could be used for further analysis. It is evident that all the items measuring the variable strategic decisions were viable and reliable to be used for further analysis. As evidenced in table 2, KMO (0.834) was greater than 0.5 thresholds, and Bartlett's Test was significant.

Table 2: Factor Analysis for Strategic Decisions

\begin{tabular}{|c|c|c|c|}
\hline & 1 & 2 & 3 \\
\hline $\begin{array}{l}\text { Top management ensures the presence of quality improvement designs in form } \\
\text { of structure, allocation of resources and quality culture }\end{array}$ & .843 & & \\
\hline \begin{tabular}{|l|l} 
Top Management plays a critical role in all key strategic decisions \\
\end{tabular} & .799 & & \\
\hline University top management provide guidelines to the adoption of QMPs & .786 & & \\
\hline $\begin{array}{l}\text { Top management incorporates 'quality vision' into the goals and objectives of } \\
\text { the university }\end{array}$ & .683 & & \\
\hline $\begin{array}{l}\text { Non-managerial employees make significant contributions to university } \\
\text { strategic decisions }\end{array}$ & .658 & & \\
\hline Top management are involved in decisions about university expansions & & .927 & \\
\hline Top management make decisions on all capital investments of the university & & .868 & \\
\hline $\begin{array}{l}\text { Top management decision-making and past performance affect future decision- } \\
\text { making processes and outcomes of our university }\end{array}$ & & & .883 \\
\hline Strategy implementation is integrated within quality management practices & & & 688 \\
\hline $\begin{array}{l}\text { Top management incorporates strategic decisions on income generating } \\
\text { projects for the university }\end{array}$ & & & .668 \\
\hline Total Eigen Values & 5.427 & 1.605 & .843 \\
\hline$\%$ of variance & 54.273 & 16.048 & 8.426 \\
\hline
\end{tabular}




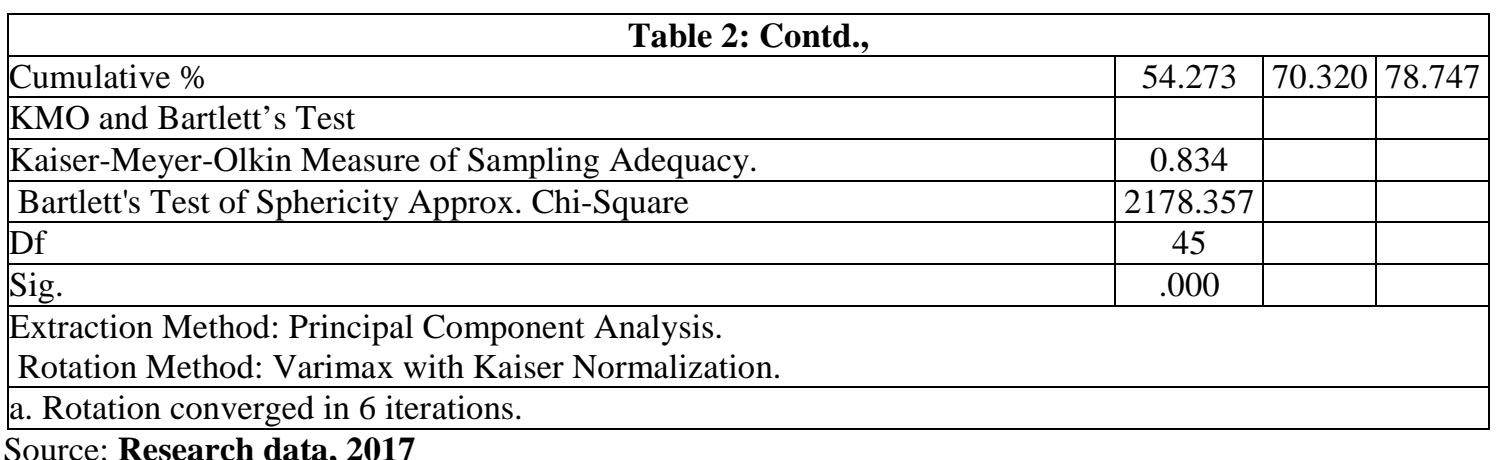

Figure 1 shows the Effect of Strategic Decisions on Universities Performance as follows

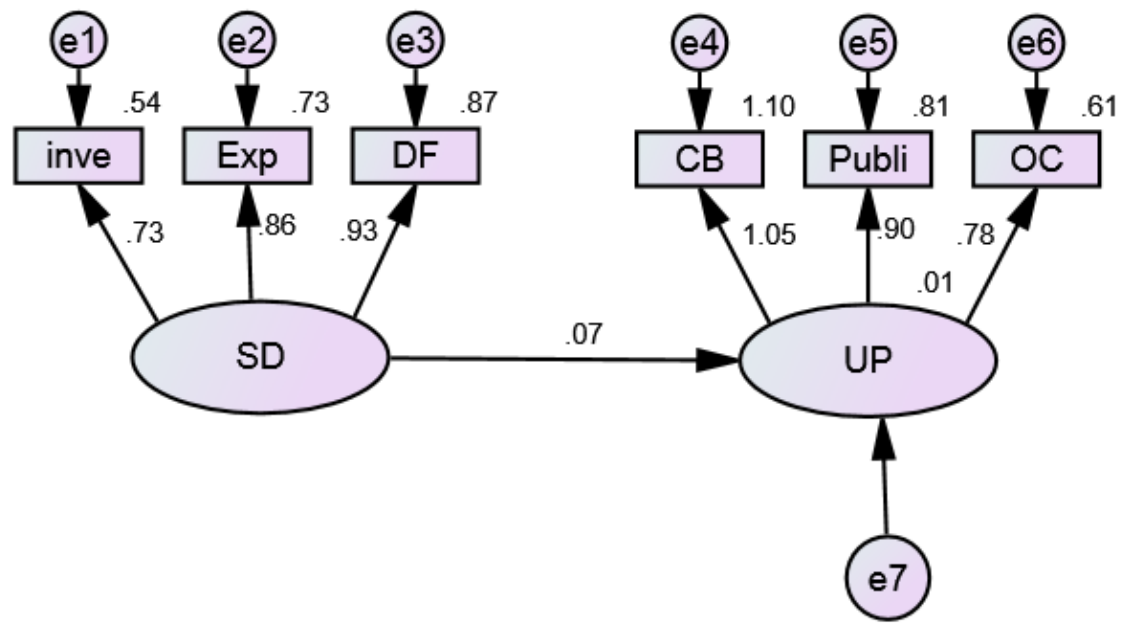

Figure 1: Strategic Decisions and University Performance

\section{Source: Research data, 2017}

The results of the model in figure 1 indicated the path coefficient between strategic decisions (SD) and university performance (UP) was 7\%. The interpretation of these results indicated that strategic decisions related positively to university performance. Top management in universities should make strategic decisions that have a positive long term effect on performance of universities. Figure 1 further indicated that diversification had the highest contribution in terms of decisions that affect performance while collaboration had the highest contribution in terms of performance of universities.

The results indicated that chi square statistic was statistically significant (CMIN/DF .458 p-value $=.886$ ). The normed chi-square was within the acceptable threshold of 3.00 (Kline, 1988). Other fit indices NFI= .998, CFI= 1.000 TLI $=1.006$ were within the acceptable threshold of above .90 (Suhr, 2006). The parsimony - adjusted measurements were above the threshold of 0.5 (PNFI=.532 PCFI = 533) and RMSEA (. 000) was within the acceptable threshold of RMSEA<. 05 (Alavi \& Ghaemi, 2011). The hypothesized model appears to be a good fit to the observed data.

\section{Hypothesis Testing}

Ho: There is no significant relationship between strategic decisions and performance of universities

This hypothesis was testing the direct effect of strategic decisions on the performance of Kenyan universities. The 5\% level of significance was taken as the level of decision criteria whereby null hypothesis was rejected if the p-vale was greater than 0.05 and fail to reject if otherwise. The study results indicated that strategic decisions had a negative 
significant effect on performance of universities (path coefficients $=-.168$ ). The RMSEA $=.000<.05$ indicated a very excellent approximate fit. This implies that university performance decreases -.011 for each 1.00 increase in strategic decisions that are poorly done. From these results, we reject the null hypothesis that there is no significant relationship between strategic decisions and performance of universities and affirm that strategic decisions have a significant relationship with performance of universities.

\section{DISCUSSION OF FINDINGS}

The results of the present study suggest a number of new insights on strategic decisions, quality management practices and university performance. The main aim of this study was to investigate the effect strategic decisions and quality management practices on university performance. The overall results obtained from the structural path analysis have proven that strategic decisions do have a significant effect on university performance.

Based on empirical studies about performance of universities in Kenya, the study confirmed the relevance of implementation of quality management systems which was once for manufacturing firms in the education sector would eliminate the quality gaps that affect performance of universities in Kenya. Empirically, studies have found that top executive influence strategic decision and organization outcomes improve (Nooarie, 2012). This study conceptualized that strategic decisions (expansion, diversification and investment) have a direct effect on performance of universities. The Maximum Likelihood Estimates of regression weights results showed that this relationship was significant ( $\mathrm{p}=.049$ ). The researcher rejected the null hypotheses $\left(\mathrm{Ho}_{1}\right)$ that there is no significant relationship between strategic decisions and performance of universities. The study, therefore confirmed that strategic decisions affect university performance directly. The final structural model results of the strategic decisions and university performance regression weights and factor loading were above the threshold of $\mathrm{R}^{2}>.50$ and of 0.60 respectively. These findings concur with Kim (2012) who empirically demonstrated and supported the argument that top executives make critical strategic decisions which have an impact on organizational performance. The finding of this study also concurs with Nooraie (2012) who found out that strategic decisions are very important and they play vital roles in an organization.

Making strategic decisions is a crucial role of top management in the university who has to ensure that strategic decisions are taken into account not in isolation, but with other environmental factors facing universities in the $21^{\text {st }}$ century such as competition, technology, online programs and globalization, among others. The majority of universities in Kenya rely on tuition fees as their major source of income. Universities do not exist in a vacuum. However, due to the current drivers of change, university management today has to conduct an environmental scan to identify other sources of funds to improve the performance of universities. The systems theory is very practical here because the environmental factors affecting universities are a key to their success, growth or performance. The university functional systems have to work in tandem with the vision and mission to achieve their goal(s).

The major aim to a quality management system is to ensure that all parts of the system with the organizational work towards achieving the major goal of the university. The current study was in agreement with the findings of Papadakis et al., (1998), that expansion decisions like introducing a new program should be done, based on market demand. The Commission for University Education (CUE) is concerned with issues pertaining creation of satellite campus by universities. The crackdown comes amidst a proliferation of institutions of higher learning, some which have been accused of offering substandard courses (Makabila, 2014). CUE has taken tremendous measures to ensure that quality of degrees offered in universities meets the demands of the employer. Employers in various industries today would wish to 
get graduates who are able adapting to the changing workplace culture, being innovative, in a position to use their capabilities and skills learned in their studies to evolve with the changes in organizations and the business world.

Wanzala (2013) in his study was of the view that, the expansion of universities has been done by un-proportional resources, that have led to quality gaps. These findings are in agreement with the current study because the researcher found that some universities had made several strategic decisions (expansion, diversification and investment) in order to improve university performance. For instance, University of Nairobi, in order to improve on their financial resources, the university has diversified to other unrelated businesses, for example: University of Nairobi Enterprise Services Ltd (UNES), have developed a business centre, a bookshop, hotels within the university and has ventured into production of agricultural products. The researcher is in agreement with Okwere and Mbeche (2014), who observed that, the stability of the operating environment is unpredictable; therefore there is a need for top management in universities, to adopt a new paradigm shift on strategic decision making. It is evident that this study has brought new knowledge by breaking through what earlier researchers have relied on untested assumptions on the link between strategic decisions and organizational performance.

\section{CONCLUSIONS}

The first objective of this study was to establish the relationship between strategic decisions and performance of universities. In support of the expectations of the study, findings indicated that strategic decisions had a significant effect on performance of universities. The first hypothesis $\left(\mathrm{Ho}_{1}\right)$ suggested that there is no significant relationship between strategic decisions and performance of universities.

The results of this study found a significant relationship between strategic decisions and performance of universities. Therefore the first hypothesis $\left(\mathrm{Ho}_{1}\right)$ was rejected. Based on the above results, it can be inferred that these findings validate the conceptualized framework as they shed some light that strategic decisions have a significant effect on performance of universities in Kenya. The study enhances the importance of top leaders in universities to ensure that strategic decisions fall in line within their goal/corporate objectives. Strategic decisions are critical to improve performance of an organization. These findings concurred with other findings from other researchers who empirically demonstrated and tested the argument that decisions made by top leadership are crucial to enhance performance of an organization. The study found that university leadership has to identify proper strategic decisions (investment, diversification and expansion) that fit the need of their universities. The results indicated that investment and diversification had a significant relationship with performance while expansion, the relationship was found to be insignificant.

\section{Contribution of the Study}

The theoretical implications of this study indicate that it is one of the few studies, which aimed to measure the components of strategic decisions its relationship with performance of universities within a developing country.

Strategic decisions directly affect the performance of universities. Therefore, efficiency and effectiveness of universities can be enhanced through implementation of strategic decisions. This study identified three strategic decisions constructs (diversification, expansion and investment) that researchers can adopt for future empirical studies.

\section{RECOMMENDATION FOR FUTURE RESEARCH}

This study has looked at the effects of strategic decisions and quality management practices on the performance of 
Kenyan universities. The researcher recommends that another study to be conducted in other sectors/industry to test the conceptual model of this current study.

\section{REFERENCES}

1. Amason, A.C. (1996). Distinguishing the effects of functional and dysfunctional conflict on strategic decision-making: Resolving a paradox for top management teams. Academy of Management Journal, 39(1), 123-148.

2. Alavi, M., \& Ghaemi, H., (2011). Application of structural equation modeling in EFL testing: A report of two Iranian studies. Language Testing in Asia, 1(3).

3. Arsham, H. (2010). Leadership decision making. Retrieved on October 23, 2016 from http://home.ubalt.edu/ntsbarsh/oper640

4. Astley, G., \& Van de Ven, A. (1983).Center perspective and debates in organizational theory. Administrative Science Quarterly, 28, 245-273.

5. Barney, J. (1991). Firms Resources and Sustained Competitive Advantage. Journal of Management, 17(1), 791-400.

6. Blustain, H., Goldstein, P., \& Lozier, G. (1998).Assessing the New Competitive Landscape. Cause Effect, 21(3), 19-27.

7. Cheng, L., Wang, Z. W., \& Zhang, W. (2011). The effects of conflict on team decision making. Journal of Social behaviour and personality, 39(2), 189-198.

8. Cooper, D. R., \& Schindler, P. S. (2014). Business Research Methods. New York, NY: McGraw-Hill,

9. Eisenhardt, K. M., Kahwajy, J. L., \& Bourgeois, L. J. (1997). Conflict and strategic choice: How top management teams disagree. California Management Review, 39(2), 42-62.

10. Finkelstein, S., Hambrick, D. C., \& Cannella, A. A. (1996).Strategic leadership. Top executives and their effects on organizations. St. Paul, Minn.: West.

11. Hambrick, D. C. (1987). The top management team: Key to strategic success. California Management Review,30(1), 88-108.

12. Hair, J. F., Black, W. C., Babin, B. J., Anderson, R. E., \& Tatham, R. L (2006).Multivariate data analysis. Upper Saddle River, New Jersey: Prentice Hall.

13. Kantardjieva, M. (2015).The Relationship between Total Quality Management (TQM) and Strategic Management. Journal of Economics, Business and Management, 3(5).

14. Kariuki, M. W. (2014). Competitive strategies used by commercial banks in Kenya to attract corporate customers (MBA Thesis). University of Nairobi.

15. Kim. D., Kumar, V., \& Kumar, U. (2012).Relationship between quality management practices and innovation. Journal of Operations Management, 30, 295-315.

16. Lynch, R., \& Baines, P. (2004). Strategy development in UK higher education: towards resource-based competitive advantages. Journal of Higher Education Policy and Management, 26(2), 171-187.

17. Makabila, S. (2014). We are coming for you bogus university warned. http://www.standardmedia.co.ke/lifestyle/article/2000137926/we-are-coming-for-you-bogus-universities-warned

18. Mueller, C. G., Mone, M. A., \& Barker, V. L. (2007). Formal Strategic Analyses and Organizational Performance: Decomposing the Rational Model. Organization Studies, 28(06), 853-883.

19. Nemat, A. R., (2010). Impact of Resource Based View and Resource Dependence Theory on Strategic Decision Making. International Journal of Business and Management, 5(12). 
20. Nooraie, M. (2012).Factors influencing strategic decision making. International Journal of Academic Research in Business and Social Sciences, 2(7).

21. Okwiri, O., \& Mbeche, I. M. (2014).ISO 9001 Certification Status and Organizational Quality Maturity. International Journal of Business and Social Science, 5(10).

22. Papadakis, V. M. (1998). Strategic Investment Decision Processes and Organizational Performance: An Empirical Examination. British Journal of Management, 9, 115-132.

23. Papulova, E., \& Papulova, Z., (2006). Competitive strategy and competitive advantages of small and midsized manufacturing enterprises in Slovaki.E-Leader, Slovakia

24. Peteraf, M. A., \& Barney, J. (2003).Unravelling the Resource Based Tangle. Managerial and Decision Economics, 24, 309326.

25. Rehman, R. R., Khalid, A., \& Khan, M. (2012).Impact of Employee Decision Making Styles on Organizational Performance: In the Moderating Role of Emotional Intelligence World Applied Sciences Journal17(10), 1308-1315.

26. Tarus, B. K. (2014). Effects of Job Rotation Strategy on High Performance Workplace, in Lake Victoria North Water Services Board, Kenya. International Journal of Business and Management, 9(11).

27. Wanzala, W. (2013). Quest for Quality and Relevant Higher Education, Training and Learning in Kenya: An Overview. Education Journal, 2(2), 36-49.

28. Wernerfelt, B. (1984). A Resource-based view of the firm. Strategic Management Journal, 5(2), 171-181.

29. Westphal, J. D., \& Fredrickson, J. W. (2001). Who Directs Strategic Change? Director Experience, the Selection of New CEOs and Change in Corporate Strategy, Strategic Management Journal, 22(12), 1113-1137. 